\title{
Research on the Remaining Problems and Solutions for Management Policy of Academic Lecturer at Public Universities in Vietnam
}

\author{
Guandong Song \\ Institute of Education Economy and Management \\ Northeastern University \\ Shenyang, China 110819
}

\author{
Van Huy Thang \\ Institute of Education Economy and Management \\ Northeastern University \\ Shenyang, China 110819
}

\author{
Thi Hoang Anh Le \\ Master of Business Administration \\ Northeastern University \\ Shenyang, China 110819
}

\begin{abstract}
This paper analyzes remaining issues and proposes solutions to improve the policy content of developing public university's lecturer in Vietnam based on the theoretical study and the results of survey on the current state, with reference to the management policy of lecturers at public university in Vietnam, including policy on planning the lecturer, policy on attracting and recruiting lecturers, policy for using and evaluation, policy of training and fostering for lecturer and policy of remuneration and honor system for lecturer.
\end{abstract}

Keywords-faculty management policies; public universities; Vietnam

\section{INTRODUCTION}

Over the past years, the State of Vietnam has issued many guidelines and policies for developing the university lecturers, creating favorable conditions and environment for the effective organization and implementation of Education and training activities. It has contributed to attracting high quality human resources and increasing the size and quality as well as to the structure and proportion of university lecturers. However, due to many reasons, these policies have not really met the requirements of developing university lecturers in the new situation, in which the main cause is the incompletion and overlapping of the development policy of public university. In particular, there was lack of important and appropriate policies and implementation framework, which are systematic, dynamic and flexible in the direction of linking with the demand of the training situation and international integration.

\section{REMAINING ISSUES IN THE POLICY OF THE MANAGING UNIVERSITY'S LECTURER AT PUBLIC UNIVERSITY IN VIETNAM}

\section{A. Policy on Lecturer's Planning}

In terms of the Schedule on the Development of Vietnam's Human Resources during 2011-2020, Decision 1216/ QD-TTg dated 22 July 2011 by the Prime Minister approving the Master Plan on the Development of Vietnam's Human Resources during 2011-2020 identify that: "Until 2015 , the number of university lecturers is about 62.1 thousand, of which PhDs are about 23\%; by 2020, the number of university lecturers will be about 75.8 thousand, of which the proportion of the number of lecturers will be about 30\%." In fact, in the academic year 2015-2016, the number of university lecturers is 69,591 , of which the doctoral degree is $14.12 \%$ (25\% strategy and $23 \%$ plan). This proves that the plan is not close to reality, reaching only $61.39 \%$ of the target (even only the quantitative survey) and the effectiveness of policy for developing university by lecturers is not high.

Due to the unreasonable planning of the public university lecturers in Vietnam, the implementation process has not been adjusted in time; the other documents related to the planning for the development of lecturer and educational administrators at a certain level, which are not suitable with reality, mainly concern and solve short-term problems and do not take into account the long-term strategy of the educational system and the country. This not only derive a small impact on the development of lecturer staff in the process of integration, but also effect on the process of training high quality human resources according to international standards. 


\section{B. Policy on Attracting and Recruiting Lecturers}

1) Policy on attracting lecturer: the policy of attracting public university lecturers in Vietnam is not effective yet because the demand for material and spiritual benefits and other assurance conditions are not attractive enough: about not only the salary, working facility, equipment, but also a scientific and democratic working environment which need to be convenient for lecturers to work and dedication. When the majority of public university lecturers in Vietnam are still hard, they have not been able to escape the vicious circle of "bread and butter", so they are difficult to dedicate with their whole heart.

In fact, implementing the policy of attracting good lecturer is now a difficult issue, because there are many barriers. There are two typical factors: First, the environment, working conditions (including facilities for training and scientific research and professional learning environment); secondly, the policies for lecturers (especially wages, bonuses, other incentives...) are not strong enough, not attractive enough to attract and retain good lecturers, let them stick with the development of university education and training in Vietnam. The policies are impossible to practice because of it still, generally, not concretized as policies on income incentives, housing...

2) Policy on recruiting lecturer: the overlapping between Decree 115/2010 / ND-CP of the Government and Joint Circular No. 47/2011/ TTLT-BGDDT-BNV of the Ministry of Education and Training and the Ministry of Home Affairs regulates the authority of managing the number of employees is different from Decree No. $41 / 2012 / N D-C P$ of the Government stipulating the positions of public service department. That differences lead to the problematic execution in decentralizing the recruitment of officials and lecturers, while still confused in the process of organizing the implementation of new recruitment contents prescribed in the Civil Servant Law and guiding documents. The selection of exam subjects ensures a relatively comprehensive examination of the knowledge, understanding and competency of the candidates. However, with the exam structure, the uniform format, uniformly applied to all the different areas is not feasible.

Psychology and social concept in Vietnam is also a barrier for pedagogical professors and lecturers due to hard work and low income. Therefore, the source for recruiting public university lecturers is still small and not excellent. It is very difficult to recruiting $\mathrm{PhDs}$, masters, so in order to get a sufficient number of lecturers, many universities have to recruit people with bachelor degrees and then send them for higher education such as master's and doctoral degrees. However, when they finish school, they are looking for ways to work with higher income.

There are distinguishing between candidates, which graduate in domestic and foreign country, resulting in the waste of human resources quality. It should take into account the benefits of value and time when recruiting good lecturers with international standards to work immediately with the recruitment of graduates need to invest funds and time from 5-7 years to work.

\section{Policy for Using and Evaluating}

1) Policy for using: the policy on the use and assessment of lecturers and regulations on the rights and obligations of lecturers is the same as for officials and employees in state agencies, which are not suitable to the nature and characteristics of lecturers, because it leads to the "administrative" status of the organization and operation of the university. The policy is lack of orientation, tectonics, lack of practicality, unable to creating the favorable environment and working conditions for the lecturers, not linking the teaching staff and the training industry across the country. Moreover, the policy of transferring lecturers to assist newly established universities are not balanced with the proportion of teaching time with scientific research duration, duration of training, fostering and field trips.

The framework of employing public university lecturers nowadays does not bring into full play the potential of both lecturers and individuals, failed to stimulate professional development; the use of qualified faculty has not yet formed a standardized process, lacking the initiative of faculty and department, and has not provided the motivation for the faculty to strive and promote their potential.

The "staffing policy" has prevented the sense of selfdevelopment of the lecturer and has not created the commitment of teachers to ensure the work. It does not really associate the rights and obligations of faculty members with the faculty and the university. Implementing the staff downsizing policy under Decree 108/2014/ND-CP by the Government has faced many difficulties and shortcomings when implementing, such as aging problem, unbalance between degree and capability, and the evaluation is not public and transparent... so the effectiveness of this policy is not high.

2) Policy for evaluation: policy formulation for the development of public university faculty has not fully aware an important principle of faculty assessment which are: description and evaluation of job placement by detail and full position. So far, there is no legal document that fully describes the job of the university lecturer. It fails to deliver the full description and detail of activities of the public university lecturers has not been fully described.

Regulations for evaluation are usually conducted within the lecturers without the participation of students, which not consider the working quality of the teacher through the results and learning of students. In addition, lecturers are often afraid to give comment and evaluate colleagues, especially with the election of the titles of emulation at the end of the school year.

The policies on assessment are still formal, not reflecting the true substance of university academic staff. There is lateness in mechanism's renewing, methods and procedures for evaluating, appointing, dismissing or resigning the academic staff in a public university. 


\section{Policy of Training and Fostering for Lecturer}

Over the past 10 years, the Government and the Ministry of Education and Training has developed and implemented many programs to send thousands of educators for study in advanced countries such as "Project 322", "Project 911", and "Project 165". However, the biggest shortcoming of these projects is the lack of interest in incentives to attract, use and recruit overseas students after graduation. Learners are well invested by the State, but after returning home, they cannot promote their ability in the unfavorable environment. The general psychology of most of the academic staff and administrative staff sent abroad for training is making a comparison in terms of income and treatment options. So many academic staff accepts to pay compensation to stay abroad for working. Thus, mechanisms and policies on recruitment and training in foreign countries, especially the benefit of academic staff now have many loopholes, being exploited and causing many lawsuits.

Mechanisms for the implementation of training projects when sending staff, lecturers to study abroad have some difficulties and shortcomings, for instance: Lecturers participate in short-term courses are unfamiliar with the environment and study methods, the short duration and need a translator, participants are from many majors... For that reason, the result of the short-term training program and the efficiency is not high.

In fact, the policy of training and retraining for university academic lecturers is not effective. The training requires a long time, money and effort. On the other hand, there is lacking in the quantity and quality of academic staff while the teaching volume is large, so there is no time for training, consequently it has influenced the quality of teaching and scientific research.

In addition, policies related to training and fostering are currently lacking mechanisms to attract the participation of enterprises in training cooperation for lecturers or instructors to practice, internship, scientific research and technology transfer. It has not raised the issue of training according to job demands, job placement training, and on-the-job training. There is no policy to attract support from international experts in training for academic staff in Vietnam; the exchange of lecturers at home and abroad is limited.

\section{E. Policy of Remuneration and Honor}

1) Remuneration policy: up to 2016 , the minimum wage of officials and employees has been adjusted increase 11 times, in fact, the salary increase only to offset the growing of consumer prices, but cannot improve the living standard. From the global perspective, there is no country like Vietnam refer to the coefficient of salary policy and salary system on a flat scale. Salary is default calculated for regular staff, regardless of professional qualifications and performance of each different person. The current Vietnam's salary system is designed for the subsidy period. The more improvements by changing the allowance and payment scale, the more inadequate in the salary system.
The level of incomes of the university lecturers has not reached the average level of society, has not really become a motive factor, and has not significantly contributed to the objective of state administrative reform. Indeed, there are two bad consequences: Firstly, many lecturers are satisfying with salaries and incomes so they feel smug about their job, therefor they are becoming dependence on the State, lack of dynamism and creativity; Secondly, more and more public university teachers change to other jobs for higher incomes.

2) Honoring policy: the recognition of the title of professor or associate professor has some limitations that need to be overcome: The title recognition and the appointment of titles have not yet been thoroughly done in order to associate with the efficiency and quality of performing the tasks. Although there are common standards, but the consideration of the title of Professor, Associate Professor is not equal between the councils. Compared with the advanced countries over the world in regards to this criteria, Vietnam has to put more effort to meet the standard.

In Vietnam, both the policy and the practice are in contrast with the world's general principle, for example: Professor, Associate Professor is just a title, not position, and the title is valid for life. In advanced countries, professors and associate professors are position, having the term of undertake in universities or institutes; the appointment of professors or associate professors is not tied to the specific needs of the university; there are many standards but not practical, especially not paying attention to international publication; Many criteria are highly appreciated internationally such as: scientific service - participation in the review committee, editorial board, presided over conference, scientific seminar, guest conference report and joining professional associations is not highly considered in Vietnam.

In addition, the work of emulation, praise still in slow innovation, also bearing "awards just for show", consisting many rewards and not relevant to the real performance, has not really become the motivation to promote the striving of the university's academic staff.

\section{SOlutions For COMPLETING THE POLICY ON DeVelopment of ACADEMic StafFs at Public UNIVERSITY IN VIETNAM}

\section{A. Building the Plan for Lecturer Development in a Public University}

Based on the planning of university education and development of the national human resource, the Ministry of Education and Training established a planning for developing lectures for the whole university education system to meet the human resource demand in the near and long future. The planning should ensure the quantity and quality as well as structure criteria, go along with the current situation in each time of the country.

In the short term, plan for developing university lecturer should focus on expanding the recruitment object in order to attract and prioritize the selection of doctoral candidates who 
are working in enterprises and domestics or international non-business units, strengthen the cooperation training with foreign universities to exchange lecturer. To take advantage of the source of visiting lecturers and seasoned trainers who are overseas Vietnamese to attend lectures to supplement and develop the academic staff in public university.

On the basis of higher education development plans, the State needs to develop general and long-term planning for the development of lecturers in the whole education and training system, each public university must comprehensive organize their academic staff, ensuring the quantity, quality and structure as well as the proportion to be suitable to the current and future human resource training needs of the country.

\section{B. Completing the Policy of Attraction and Recruitment}

Enabling a legal environment in order to creating favorable conditions for the operation of academic staff in university, in which pay attention to institutionalization the Party's undertakings and policies into social policies for building a truly pedagogic environment that respects, promotes and protects the creative working conditions and apply an appropriate remuneration policy for academic staff in public university. Completing the policy and mechanisms can help creating the best conditions for the development of the specific ability of the academic staff in the university. The State should continue to adopt policies on investment in financial resources, material and technical foundations, construction of key universities, research and experimental facilities, expansion of international cooperation, it opens up new jobs for the entire academic staff helps them work with full dedication.

From the actual needs of the job placement, completing the policy of giving autonomy and social responsibility to faculties, especially the specialized faculty of the university, seeking talent, attracting excellent lecturers who are overseas Vietnamese, foreign experts from schools, office and enterprises are qualified to participate in teaching under short-term contracts or seasonal contracts.

In terms of modification of the Civil Service Act, it's not necessary to recruit the officer for lecturer position. The study conducted to allow departments to sign a fixed term employment contract for some jobs. Through that, the lecturers can meet the work requirements as the basis, step by step to renew the working mode in the direction of dynamic, freedom and creativity. A fixed-term contract mechanism will be more flexible in regard to changing staff and will also require lecturers to work harder if they do not want to be fired. Thereby, it is necessary to create a connection and continuous flow of attracting talent from the private sector, enterprises and from abroad, in order to provide better training.

Establishing and setting up a "National Bank of lecturers" to use as a general source in the higher education system in order to avoid wasting and overlapping human resources. Creating linkages, cooperation and collaboration can help raise the level and capacity of domestic and foreign lecturers and universities. So, it is necessary to develop and complete the policy of creating a favorable and constant working environment in terms of contents, training programs and teaching languages, especially the preferential treatment regime for lecturers in public universities.

\section{Completing the Policy for Using and Evaluation}

Comprehensive reform of the policy from simply "use" to "use at an important function" the academic staff in public university based on the rules of law, contributions of university lecturers and in accordance with the rules of the market economy which related to the recruitment, job placement, payroll, career advancement. To continuously improve the conditions and pedagogical environment in order to create motivation, stimulate and encourage lecturers to work creatively and efficiently. It is necessary to build and develop the "National Trainer Bank" to develop appropriate mechanisms and tools for the effective use of university lecturers.

To formulate and implement specific mechanisms and policies to create a working environment of scientific and democratic work, to encourage talented lecturers to contribute more and more for national industrialization and modernization. Develop the Law on Lecturers and amend the Law on Education accordingly. It is necessary to clearly define the functions and tasks of the Council of University with the relevancy of the Party Committee in the university. In many countries, due to the lack of a Party organization, the Council of University performs a duty and function as prescribed. Meanwhile, in Vietnam, almost all public universities have Party organizations.

To review and rearrange the academic staff and educational administrators so as to draw up training and fostering plans in sufficient quantity and balance structure. To organize the investigation and assessment of the actual status of lecturers on professional ethics, professional qualifications, teaching methods, foreign language proficiency, information technology and management capacity in schools in the public universities.

To renovate the policy of employing academic staff along the direction of assignment, decentralization of responsibilities and powers, and granting autonomy and selfresponsibility to universities' faculties; To formulate mechanisms and policies to unify a state management in charge of university training and administration according to the mechanism of supervising the university system; establishing the Association of Lecturers of Vietnamese Public Universities; Establishing the Council of University to appoint and dismiss the Principal to professionalize the title of Principal.

Developing regulations (standards and procedures) to evaluate faculty on the basis of the level, actual capacity, results, actual work performance on that basis to treat, promote the academic staff in public university.

\section{Completing the Policy of Training and Fostering}

In order to develop the lecturer in public university, it is necessary to develop a set of "Standard teaching 
qualification for lecturer". Based on that, universities develop their strategies and plans to improve their staff in various forms: long-term, regular (doctoral, master's) training; periodical training and fostering; Self-study and fostering lecturers... so that the faculty members can improve their qualifications, suitable to their immediate and long-term job positions. To reform the policy of one-time training and fostering in order to obtain diplomas and/ or certificates for field trips or professional training sessions every five years for trainers to renew their knowledge and practical understanding.

Completing the strategy of developing the academic staff: the strategy includes the following main priorities: Positive training of faculty by sending them to study abroad under the Project 911 to achieve international qualification for key industries, new modern jobs; encourage and facilitate faculty members to participate in joint training and research programs with foreign universities; Practical training in enterprises, in cooperation with domestic and foreign research and technology transfer institutions; attract and use talented teachers regardless of nationality to work for universities. At the same time, focus on expanding the training within the country by using overseas resources (capital, technology, foreign lecturers...) to quickly train internationally-qualified teachers in short-term and build up the training potential modern to international level in the long term.

Completing the legal framework for training and fostering of academic staff (viewpoints, guidelines, regimes and policies): currently the policies show priority in training, fostering to improve the ranking criteria and the title of lecturer. This is the right direction for the civil service system, where the lecturers are classified according to class, rank. Thus, the training and fostering of the criteria set out by the class is the minimum requirement for trainers to meet the criteria of the class. Attention is needed in the employment system, which focuses on the actual capacity of the teaching staff.

Completing the policy of ensuring sources, and financial allocations for training and fostering the academic staff: in addition, it is necessary to formulate a policy of socialization of financial resources for training and fostering activities, such as mobilizing contributions from learners in accordance with the law, mobilizing resources for socialization and investment from legal organizations, individuals, enterprises from both domestic and international sources.

\section{E. Completing the Policy of Remuneration and Honoring}

Give real autonomy to higher education institutions, in which the Rector has the right to negotiate salaries and allowances with the public university faculty. Continue to improve the mechanism and conditions for granting autonomy and social responsibility for public universities. Reducing staff and at the same time encourage universities to actively raise non-business revenues from technology transfer, scientific research sources, etc., so as to cover expenses beyond the salaries and allowances for lecturers.
Implement salary policy reform, and create motivation for staffs and lecturers. In the current market mechanism, the effective use of faculty depends on many factors, but wages and salaries are the leading factor. The purpose of the lecturer is to raise income to meet their own and their family material and spiritual needs. To formulate a mechanism for paying salaries and rewards to the lecturers who have agreed on the principle of wage distribution and must attach the degree of enjoyment to the quality and efficiency of the assigned jobs.

Improve the policy of wage reform with a neatly organized and structured academic staff. There is impossible to reform salary while the system is bulky, ineffective, and unproductive. Reform of the machinery must identify each job position. On the basis of clearly defining the functions and tasks of each organization, each title and each subject taught by the academic staff in order to arrange the correct person and task. Regarding to academic staff who fail to meet the standard, move to other work or terminate the contract. To quantify the work to pay the right salary for relevant performance, which ranks and grades have been prescribed for each teacher's title.

In the treatment and honor policy, should give preferential honor for those with high performance. Annually, excellent academic staff should be rewarded based on the "student votes of confidence" and the results of the work. These staffs are honored in front of the university on important occasions, are invited to speak and share experiences to their colleague... Strengthening and maintaining the treatment policy in order and discipline to become strong spiritual and material resources for the academic staff. To reform the emulation and commendation work with the aim of promoting the competition movement in a substantive manner, overcome the "achievement disease", formalism and wasting; at the same time, building a good working environment so that the lecturers can develop their abilities and always commit themselves to the honorable profession.

Completing a mechanism for consideration and appointment of professors and associated professors: first of all, universities should have assignment right. Based on the evaluation criteria and procedures promulgated by the State, the universities shall consider and appoint the titles of professor and associate professor and be responsible for the constant examination. The State Council for Professor Title only plays the role of appraising and supervising the consideration and appointment of professors and associate professors of higher education institutions.

\section{CONCLUSION}

In order to develop the lecturer in public university, the policy system of the State plays an important role, which creates a favorable condition and educational environment, give a direction and motivation for lecturers. In this period and the future years, the State should develop and complete the policy following "open and flexible" direction, improving the autonomy and social responsibility of the lecturer and university; ensuring the possibility, fair 
competing according to the position and payment. Create consensus among faculty and society; ensure the environment and fairness among domestic and foreign lecturers, harmonize the interests and responsibilities of new lecturers, encourage foreign lecturers to teach and participate in scientific research, expand international cooperation in education and training.

\section{REFERENCES}

[1] Dang Danh Anh, Reform of the national education system to overcome current weaknesses in higher education, The Vietnam Institute of Educational Sciences, 2014.

[2] Tran Xuan Bach, Evaluating university lecturer towards standardization in the current period, Da Nang University, 2013.

[3] The Ministry of Education and Training, Project of Law of University Education, Report of University education overview, Hanoi, 2009.

[4] Nguyen Ba Can, Completing the current policy of higher education development in Vietnam, National Economics University, 2013.

[5] Hoang Van Chau, Exports of higher education services in Vietnam, Information and Communications Publishing House, 2015.

[6] Vu Cao Dam, Skill of analyzation and policymaking, The gioi Publishers, Hanoi, 2016.

[7] Nguyen Thi Thu Huong, Develop teaching staff in universities Situations and solutions, Vietnam National University Journal of Science, Hanoi, 2016.

[8] Dang Thi Minh, Policy of development the private university in Vietnam, National Academy of Public Administration, 2015. 